\title{
Resistance to burial of cyanobacteria in stromatolites
}

\author{
Jacco C. Kromkamp ${ }^{1, *}$, Rupert Perkins ${ }^{2}$, Nicole Dijkman ${ }^{1}$, Mireille Consalvey ${ }^{3}$, \\ Miriam Andres ${ }^{4}$, R. Pamela Reid ${ }^{4}$
}

\author{
${ }^{1}$ Netherlands Institute of Ecology, Centre for Estuarine and Marine Ecology (NIOO-CEME), PO Box 140, 4400 AC Yerseke, \\ The Netherlands \\ ${ }^{2}$ School of Earth, Ocean and Planetary Sciences, Cardiff University, Cardiff CF10 3YE, UK \\ ${ }^{3}$ National Institute of Water \& Atmospheric Research (NIWA), Greta Point, Private Bag 14-901, Kilbirnie, Wellington, \\ New Zealand \\ ${ }^{4}$ University of Miami/RSMAS-MGG, 4600 Rickenbacker Causeway, Miami, Florida 33149, USA
}

\begin{abstract}
Stromatolites are complex lithified structures with a well-defined layered structure thought to have been formed by trapping and binding of sediment particles by micro-organisms, especially cyanobacteria. Modern marine stromatolites in the Bahamas live in a high-energy environment (surf zone) and are regularly buried by moving sands. We investigated stromatolite cyanobacterial photophysiology ex situ, during and after sand burial using variable fluorescence studies. Buried samples inactivated their photosynthetic electron transport, but only when oxygen concentrations decreased to low levels. Post-burial, the stromatolite cyanobacterial community reactivated its photosynthetic activity within 1 to $2 \mathrm{~h}$, but this activation was light dependent. It is therefore speculated that the redox state of the plastoquinone pool determines the inactivation/reactivation processes. The ability of cyanobacteria to survive and recover from burial by sediment could be a fundamental attribute that has contributed to the success of cyanobacteria as stromatolite builders and for the actual existence of stromatolites as organo-sedimentary structures with a putative presence spanning 3500 million yr.
\end{abstract}

KEY WORDS: Stromatolite burial $\cdot$ Cyanobacteria $\cdot$ Chlorophyll fluorescence $\cdot$ PSII $\cdot$ State transition

\section{INTRODUCTION}

Stromatolites were common prior to the Cambrian diversity explosion 490 to 540 million yr ago (Awramik 1992) and were then widespread in the shallow seas. Nowadays, modern stromatolites growing in open marine environments are restricted to the margins of the Exuma Sound in the Bahamas and Shark Bay, Australia. It is thought that the well-laminated microbial structures present here are modern analogues to ancient stromatolites, although the role of eukaryotic epiphytes has not been evaluated yet.

According to Reid et al. (2000), the formation of stromatolites and stromatolite-like mats found in the Bahamas depends upon a dynamic balance between sedimentation and lithification. Three growth types (with intermediate forms) have been described (Reid et al. 2000). The non-diazotrophic cyanobacterium Schizotrix sp. dominates Pioneer Type 1. The extracellular polymeric substances (EPS) excreted by the cyanobacteria capture the sediment grains (ooids), causing the comparatively unstable mats to grow. As a result, most of the biomass is normally found below the stromatolite surface at variable depths (Fig. 1), although a significant cyanobacterial biomass can be present above this layer. Domination of heterotrophic processes leads to the formation of a micritic layer at the surface, typical for a Type 2 mat. This 20 to $60 \mu \mathrm{m}$ white layer is formed by precipitation of calcium carbonate, most likely liberated by consumption of EPS by heterotrophic activity (Viss- 


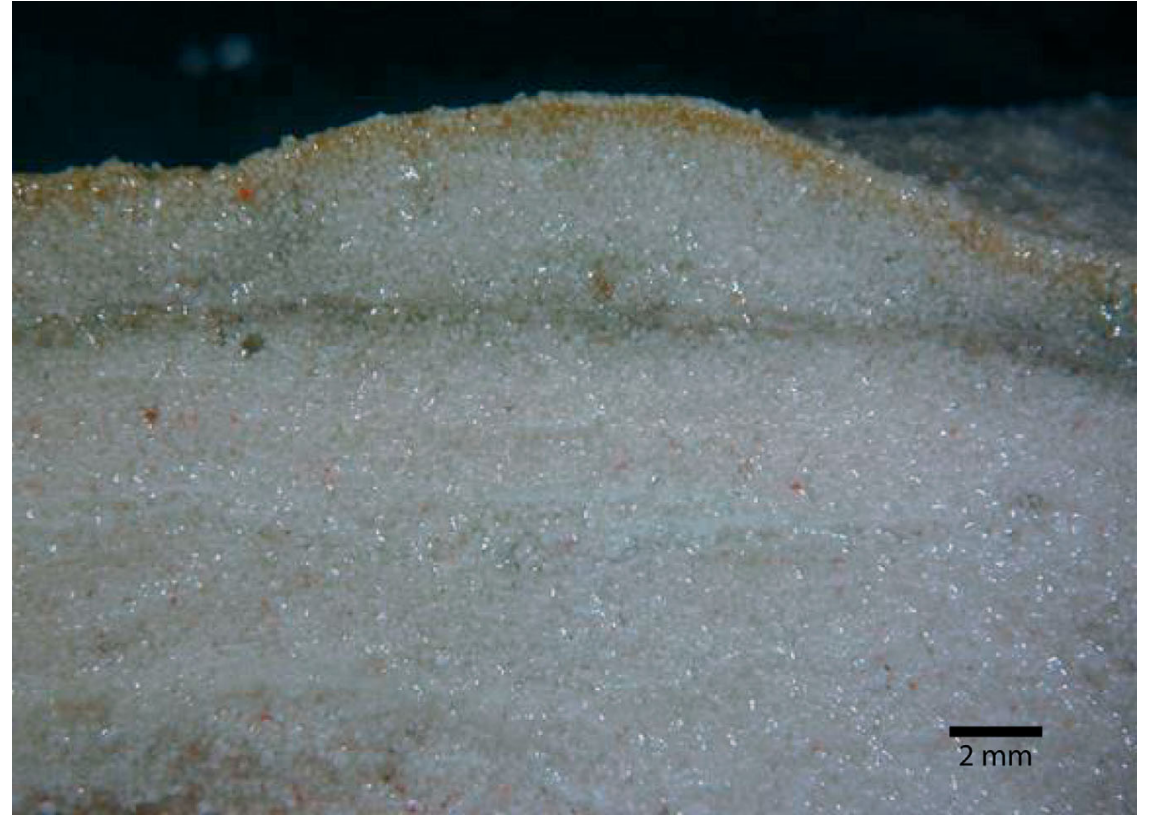

Fig. 1. Cross-section through a live stromatolite, showing the clearly visible subsurface cyanobacterial layer. The brown layer of extracellular polymeric substances directly below the surface also contains many cyanobacteria, mainly belonging to the genus Schizotrix cher et al. 2000, Paerl et al. 2001). About $15 \%$ of the mats in the vicinity of Highborne Cay are of Type 2. Another $15 \%$ of the stromatolite cyanobacterial mats are of Type 3, the climax community state. These mats obtain their stability by the endolithic unicellular cyanobacterium Solentia sp., which bores into the ooids and by this process fuses the sand grains together. The Solentia spp. are found beneath the Schizotrix surface layer (Macintyre et al. 2000, Reid et al. 2000).

Stromatolites in the Bahamas can be found in a highenergy environment, i.e. in the low intertidal and subtidal waters behind small algal reefs on the east side of the islands, facing Exuma Sound. Despite the shelter provided by these small reefs, strong currents, passing storms and hurricanes move large amounts of sand, regularly exposing and burying the stromatolites and mats. Burial will most likely induce heterotrophic conditions leading to a Type 2 mat. This is supported by observations that mats dug out from under the sand have the whitish appearance characteristic of the micritic layer characteristic for Type 2 communities (J. C. Kromkamp \& R. Perkins pers. obs.). What is the fate of the buried autotrophic communities? Examination of naturally buried samples (length of burial not known) indicates a loss of the epiphytic surface community (mainly diatoms), but an apparent persistence of the subsurface cyanobacteria. How do the cyanobacteria survive this dynamic process of burial and exposure? Do they inactivate their photosynthetic activity or do they just die, being replaced by new colonisers? When they are exposed, can they reactivate photosynthetic activity, and if so how quickly? These questions are addressed in this paper.

\section{MATERIALS AND METHODS}

Sampling. All sampling was performed on Highborne Cay $\left(24^{\circ} 43^{\prime} \mathrm{N}, 76^{\circ} 49^{\prime} \mathrm{W}\right)$, a small northerly island in the Exuma Cays (Fig. 2). Samples of stromatolite mats were transported in seawater in the shade and kept in a pool of running seawater collected from near the sample site. Fresh samples were collected daily. All laboratory measurements were made inside the the RV 'Walton Smith', with rapid transport from storage pools to the measurement facilities.

Assessment of photosynthetic activity. Photosynthetic quantum efficiencies were measured with a DIVING-PAM (Walz, having a red [655 nm] measuring light [ML]) or with a WATER-PAM equipped with the fiberoptic version of an emitter-detector unit (WATEREDF/B, Walz, equipped with a blue [470 nm] ML and actinic light source). For both instruments, the saturating pulse length was set at $0.6 \mathrm{~s}$ and the light intensity exceeded 3500 to $4000 \mu \mathrm{mol}$ photons $\mathrm{m}^{-2} \mathrm{~s}^{-1}$, as measured with the DIVING-PAM light sensor, which was calibrated against a LiCor LI-190 irradiance sensor. In the dark, the maximum quantum efficiency of photosystem II (PSII $\left.F_{\mathrm{v}} / F_{\mathrm{m}}\right)$ is calculated as $F_{\mathrm{v}} / F_{\mathrm{m}}=\left(F_{\mathrm{m}}-\right.$ $\left.F_{0}\right) / F_{\mathrm{m}}$, where $F_{\mathrm{m}}$ is the maximum fluorescence yield and $F_{0}$ is the minimum fluorescence. In the light, the apparent or operational PSII quantum efficiency is calculated as $\Delta F / F_{\mathrm{m}}{ }^{\prime}=\left(F_{\mathrm{m}}{ }^{\prime}-F\right) / F_{\mathrm{m}}{ }^{\prime}$, where $F$ and $F_{\mathrm{m}}{ }^{\prime}$ are the operational and maximum fluorescence yield measured in the light (Genty et al. 1989). Relative electron transport rates (rETR, relative due to the inability to measure the light absorption coefficients) and the exact light level to which the cyanobacteria were 


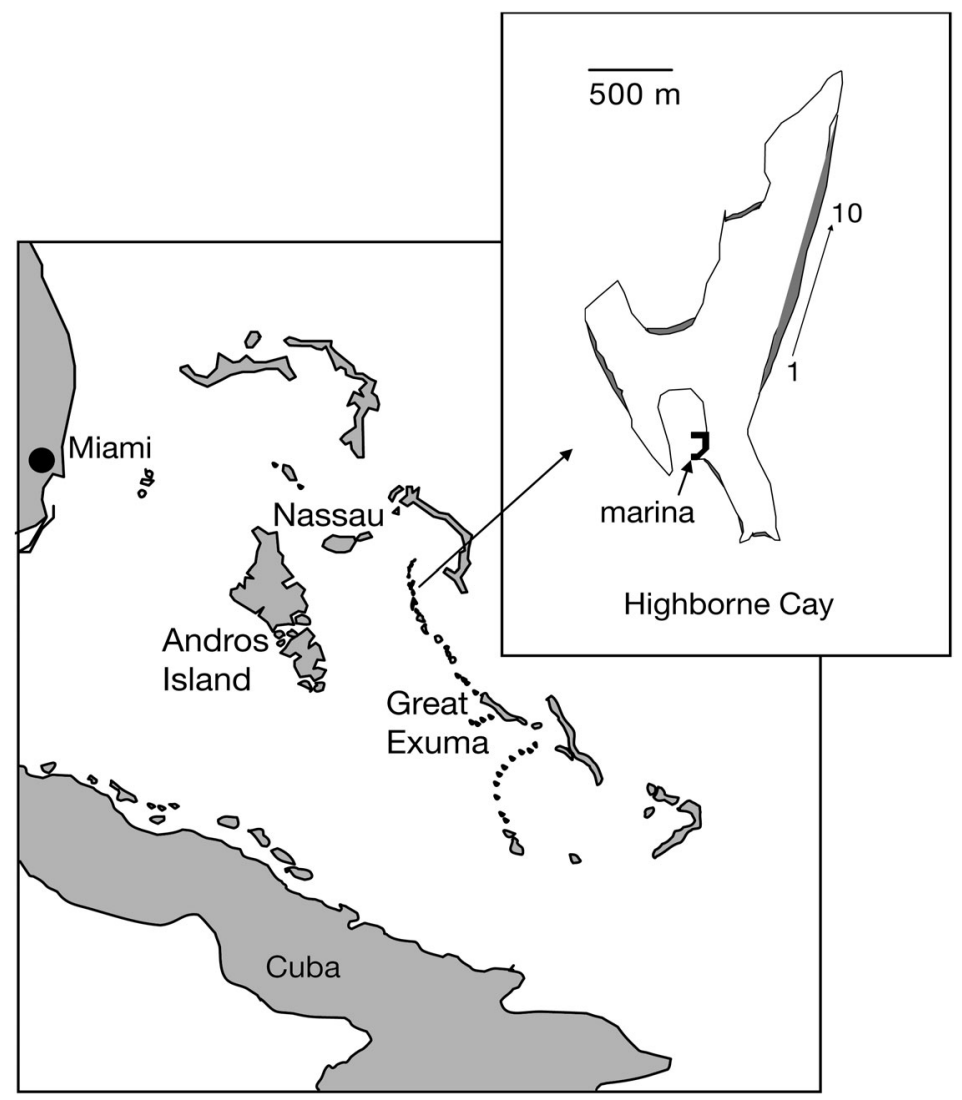

Fig. 2. Approximate location of the sampling stations (1 to 10) on Highborne Cay, an island of the Exuma Cays, Bahamas. Most stromatolites were found in subtidal waters and in the surf zone at depths of up to $2 \mathrm{~m}$. The grey areas on Highborne Cay are beaches

exposed (Sakshaug et al. 1997, Perkins et al. 2002, Forster \& Kromkamp 2004, Consalvey et al. 2005) were calculated from rapid light curves (RLC) calculated as $\mathrm{rETR}=\Delta F / F_{\mathrm{m}}{ }^{\prime} \times E$, where $E$ is the irradiance generated by the internal PAM light sources. Depending on the size of the stromatolite samples (approximately 10 to $30 \mathrm{~cm}^{2}$ ), 3 to 6 RLCs were made per sample, using a $2 \mathrm{~mm}$ spacer to keep the distance to the stromatolite surface as constant as possible. The stromatolites were dark adapted for approximately 30 to $45 \mathrm{~min}$. No fluorescence measurements were made on spots where epiphytic diatom growth was visible. RLCs performed on reactivated stromatolites were made after $1 \mathrm{~min}$ of dark adaptation. RLCs were developed to probe the photosynthetic activity at in situ conditions, and rates of rETR at low irradiances may be influenced by processes inducing non-photochemical quenching (Serôdio et al. 2005, Perkins et al. 2006). Preliminary results showed that when the length of the light steps varied between 20 and $120 \mathrm{~s}$ this did not influence the shape of the RLC. This suggested that acclimation to each light did not play a role during the RLC. We used a 30 $\mathrm{s}$ exposure time for each irradiance value. The light curves were fitted using the model of Eilers \& Peeters (1988). From the fits the relative maximum rate of electron transport $\left(\mathrm{rETR}_{\max }\right)$ and the initial slope of the rapid light curve $(\alpha)$, a measure of the photosynthetic efficiency, were obtained. See Kromkamp \& Forster (2003) for more information about the fluorescence terminology followed in this paper. The PSII antenna of the cyanobacteria (with only phycocyanine) absorbs little blue light, leading to low fluorescent yields. However, the fiberoptic version of the WATER-PAM is very sensitive due to the photomultiplier detector, and we obtained good signals with relatively low gain and measuring light settings. Despite the differences in ML colour between the 2 fluorometers, test results showed that quantum efficiencies and RLCs were not significantly different when the same positions on different stromatolites were measured.

Oxygen measurements. The oxygen concentration was measured using fiberoptic microsensors (with $140 \mu \mathrm{m}$ tip diameter; Microx TX3, PreSens). To protect the sensitive fiberoptic tip, the microsensor was put into a $0.6 \mathrm{~mm}$ syringe needle with its tip flush with the end of the needle, and the $\mathrm{O}_{2}$ concentrations were measured 1 to $2 \mathrm{~mm}$ above the stromatolite surface. The optodes were calibrated in air-saturated seawater and $\mathrm{N}_{2}$ gassed anoxic seawater. In the case of the $\mathrm{O}_{2}-$ degassing experiments (by bubbling a $370 \mathrm{ml}$ bottle with a stromatolite sample which had a $1 \mathrm{~cm}$ sand layer on the bottom), discrete water samples were taken with a $20 \mathrm{ml}$ syringe and emptied carefully into a $20 \mathrm{ml}$ scintillation vial, after which the $\mathrm{O}_{2}$ concentration was measured immediately. This water was returned to the bottle after the measurement.

\section{RESULTS AND DISCUSSION}

Fig. 3 shows the result of a burial experiment. A sample was put in a jar, the fiberoptic tip of the fluorometer was carefully placed on the stromatolite surface and then the jar was filled with site sand and water (no stirring). The maximum PSII efficiency $\left(F_{\mathrm{v}} / F_{\mathrm{m}}\right)$ declined gradually until it reached zero, indicating a complete inactivation of photosynthesis. After $870 \mathrm{~min}$ the sample was uncovered, given fresh seawater and kept in darkness, but this had little effect on $F_{\mathrm{v}} / F_{\mathrm{m}}$. Upon application of low light (upward arrow), the effective PSII quantum efficiency $\left(\Delta F / F_{\mathrm{m}}{ }^{\prime}\right)$ increased rapidly. Temporarily turning off the light (downward arrow) caused a slight decline in $F_{\mathrm{v}} / F_{\mathrm{m}}$, prior to further 


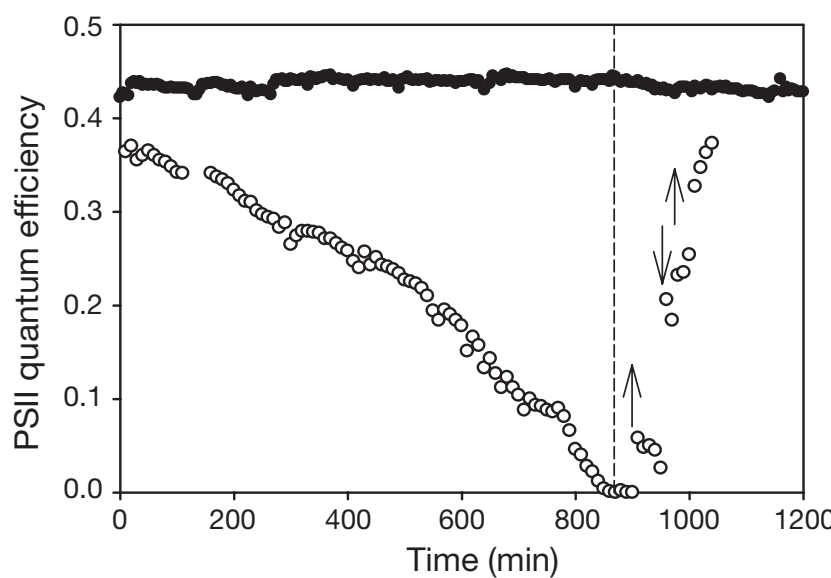

Fig. 3. Quantum efficiency of a stromatolite sample buried under $3 \mathrm{~cm}$ of site sand, followed by direct exposure to low light (open symbols). Upward arrows indicate low light on $\left(23 \mu \mathrm{mol}\right.$ photons $\left.\mathrm{m}^{-2} \mathrm{~s}^{-1}\right)$; downward arrow indicates light off. Closed symbols refer to a control sample kept in the dark but not buried. After 870 min (dashed line) the sample was uncovered. PSII: Photosystem II

recovery to initial values when the light was reapplied. A control sample kept in the dark (not buried thus allowing gas exchange with the overlying seawater) showed no change in $F_{\mathrm{v}} / F_{\mathrm{m}}$ over this $20 \mathrm{~h}$ period. A repeat of this experiment with a sample that was buried for $5 \mathrm{~d}$ showed a nearly identical recovery pattern: after $5 \mathrm{~d} F_{\mathrm{v}} / F_{\mathrm{m}}$ had dropped to zero, but when the sample was exposed to seawater in the dark a very small increase in $F_{\mathrm{v}} / F_{\mathrm{m}}$ was noted to 0.02 (Fig. 4). With the application of a low irradiance of $23 \mu \mathrm{mol}$ photons $\mathrm{m}^{-2} \mathrm{~s}^{-1}$ recovery increased more rapidly. Brief periods of darkness arrested the reactivation of photosynthesis

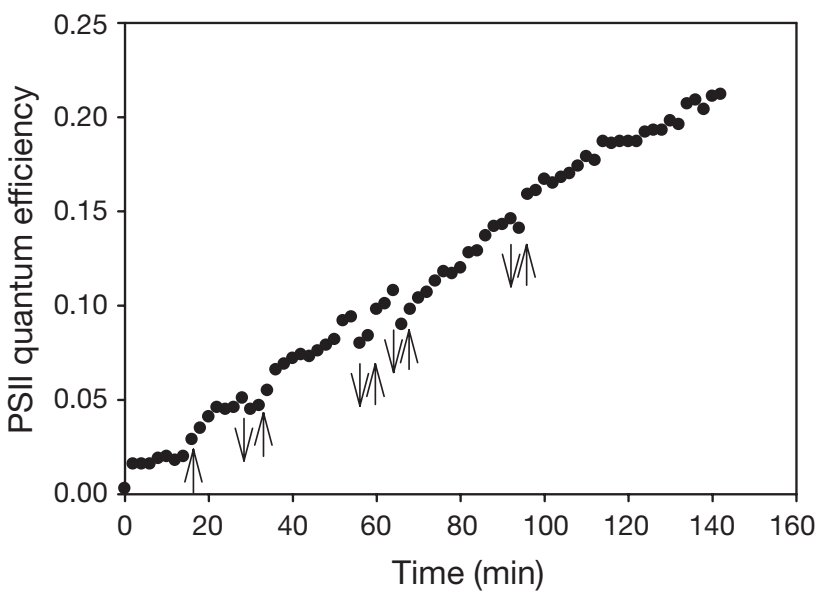

Fig. 4. Post-burial recovery in quantum efficiency of a stromatolite sample that had been buried under site sand for $5 \mathrm{~d}$. The sample was uncovered and exposed to darkness followed by low light of $23 \mu \mathrm{mol}$ photons $\mathrm{m}^{-2} \mathrm{~s}^{-1}$ in air-equilibrated seawater. The upward arrows indicate light on; the downward arrows indicate data points when the light was switched off

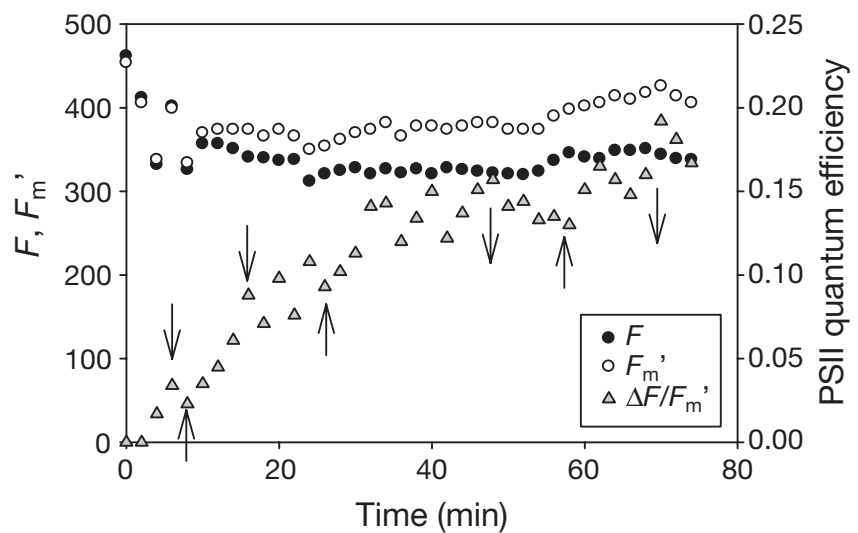

Fig. 5. Changes in $F$ and $F_{\mathrm{m}}$ ' during recovery at an irradiance of $77 \mu \mathrm{mol}$ photons $\mathrm{m}^{-2} \mathrm{~s}^{-1}$. At the downward arrows the light was temporarily turned off and was turned on again at upward arrows. Note the increase in variable fluorescence (the difference between $F_{\mathrm{m}}^{\prime}$ and $F$ ) caused by the rise in $F_{\mathrm{m}}{ }^{\prime}$, indicating a recovery of PSII activity as measured by the rise in $\Delta F / F_{\mathrm{m}}{ }^{\prime}$

in a similar manner as shown in Fig. 3. This corroborates the idea that light is necessary to reactivate cyanobacterial photosynthesis after inactivation. To test this, 2 experiments were performed. The first experiment showed recovery of PSII efficiency of a sample which was buried for $4 \mathrm{~d}$ (Fig. 5). Then, $1 \mathrm{~d}$ after the start of the burial, we measured the $\mathrm{O}_{2}$ concentration near the stromatolite surface by slowly lowering the syringe needle containing the oxygen sensor using a manual micromanipulator. Near the surface of the stromatolite the oxygen concentration was $0 \%$. Recovery was followed using a medium low light intensity of $77 \mu \mathrm{mol}$ photons $\mathrm{m}^{-2} \mathrm{~s}^{-1}$. This sample reactivated quickly: fluorescence yields dropped initially, but after $10 \min F_{\mathrm{m}}{ }^{\prime}$ rose gradually, whereas $F$ decreased slightly, and as a result $\Delta F / F_{\mathrm{m}}$ ' recovered rapidly and reached a more-or-less stable value after 50 to $60 \mathrm{~min}$. Note that on each occasion when the light was turned off for a short period recovery was arrested and commenced again when the light was re-applied. This temporary decrease in $F_{\mathrm{v}} / F_{\mathrm{m}}$ was mainly the result of a decrease in $F_{\mathrm{m}}$. In the second experiment, reactivation was followed for a sample, which had been buried under sand for $4 \mathrm{~d}$ (Fig. 6). When the microbial mat was removed from under the sand and put in fresh seawater and exposed to a very low irradiance $\left(4 \mu \mathrm{mol}\right.$ photons $\left.\mathrm{m}^{-2} \mathrm{~s}^{-1}\right)$, hardly any recovery took place during the first hour. Increasing the irradiance to $77 \mu \mathrm{mol}$ photons $\mathrm{m}^{-2} \mathrm{~s}^{-1}$ induced development of variable fluorescence, showing reactivation of photosynthesis, and $\Delta F / F_{\mathrm{m}}{ }^{\prime}$ stabilised at a rather low value of $\sim 0.06$. Turning the irradiance down after $\sim 80 \mathrm{~min}$ to $4 \mu \mathrm{mol}$ photons $\mathrm{m}^{-2} \mathrm{~s}^{-1}$ caused a decrease in $\Delta F / F_{\mathrm{m}}{ }^{\prime}$, and, upon re-application of $77 \mu \mathrm{mol}$ photons 


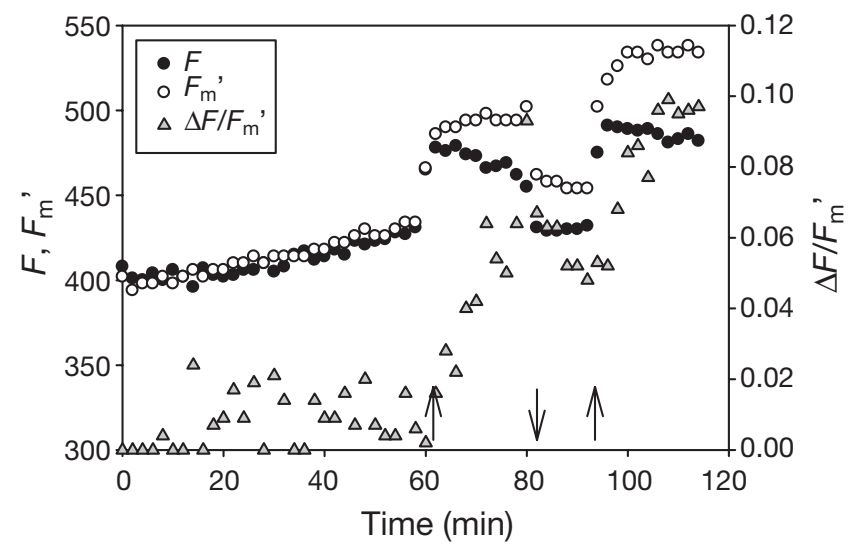

Fig. 6. Changes in fluorescence parameters during recovery in air-equilibrated seawater conditions exposed to a very low irradiance of approximately $4 \mu \mathrm{mol}$ photons $\mathrm{m}^{-2} \mathrm{~s}^{-1}$. At the upward arrows the irradiance was increased to $77 \mu \mathrm{mol}$ photons $\mathrm{m}^{-2} \mathrm{~s}^{-1}$. This induced recovery of variable fluorescence as reflected by a rise in $\Delta F / F_{\mathrm{m}}{ }^{\prime}$. At the downward arrow the light was temporarily turned off

$\mathrm{m}^{-2} \mathrm{~s}^{-1}$, the situation reversed as the sample continued to reactivate, and $\Delta F / F_{\mathrm{m}}{ }^{\prime}$ now stabilised at a higher, but still low, value of 0.1 .

These results showed that darkness alone was not sufficient to induce inactivation of the photosynthetic activity of the stromatolites, because the sample kept in aerobic conditions in the dark maintained a high $F_{\mathrm{v}} / F_{\mathrm{m}}$. As the oxygen concentration in the buried sample decreased due to heterotrophic microbial activity, it seems likely that oxygen played a role in the inactivation. This was tested by bubbling a sample in a darkened bottle with $\mathrm{N}_{2}$ gas. During the first 20 min no significant changes were observed, although the oxygen concentration dropped from 100 to $70 \%$ (Fig. 7). After

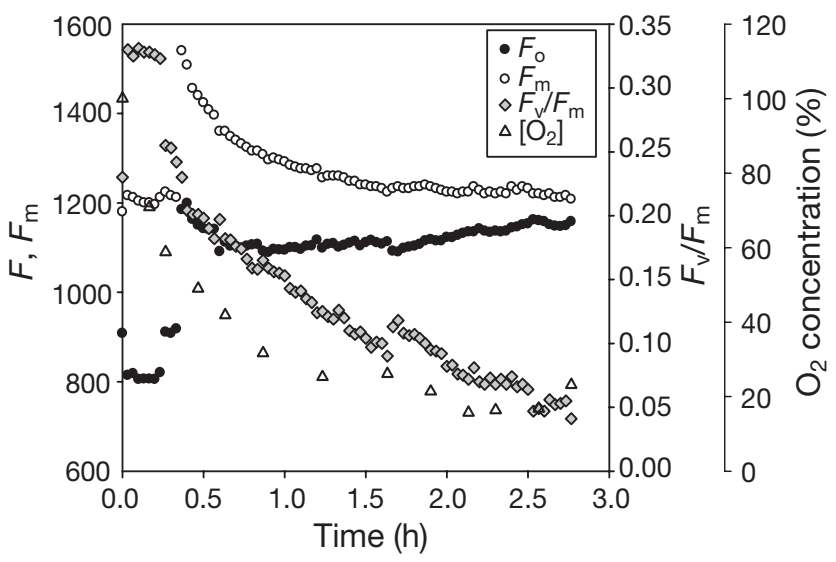

Fig. 7. Changes in fluorescence parameters and oxygen concentration during inactivation of a microbial mat put in a bottle in the dark and bubbled with $\mathrm{N}_{2}$ gas. Due to sampling, the fiberoptic probe was moved to a slightly different position above the stromatolite surface causing a jump in $F_{0}$ and $F_{\mathrm{m}}$ at about $20 \mathrm{~min}$ this time point both the minimal $\left(F_{0}\right)$ and maximal $\left(F_{\mathrm{m}}\right)$ fluorescence yields decreased, but after $0.7 \mathrm{~h} F_{0}$ started to increase slowly, whereas $F_{\mathrm{m}}$ continued to decrease. As a result the quantum efficiency $\left(F_{\mathrm{v}} / F_{\mathrm{m}}\right)$ decreased steadily. With the exception of the first $20 \mathrm{~min}, F_{\mathrm{v}} / F_{\mathrm{m}}$ was linearly correlated to the oxygen concentration $\left(\mathrm{r}^{2}\right.$ $=0.94$ ). The oxygen concentration outside the stromatolite did not drop below 15 to $20 \%$ saturation, due to minor mixing of air with the seawater because we could not close the lid of the bottle completely. A repeat of this experiment showed the same result (not shown), and when it was placed in a tray with fresh seawater and exposed to the dim light conditions in the laboratory, $F_{\mathrm{v}} / F_{\mathrm{m}}$ recovered from 0.05 to 0.25 in $1.5 \mathrm{~h}$ (not shown). A control experiment carried out in the full sunlight showed that $\Delta F / F_{\mathrm{m}}{ }^{\prime}$ did not change when the oxygen concentration dropped from 100 to $30 \%$. However, when the bottle containing the stromatolite was placed in the shade, the quantum efficiency decreased rapidly, whereas the $\mathrm{O}_{2}$-concentration showed a further, but limited, decrease from 30 to $20 \%$. When the bottle was placed in the light again, $\Delta F / F_{\mathrm{m}}{ }^{\prime}$ increased once more, while the $\mathrm{O}_{2}$ concentration remained the same. These results suggest that low oxygen conditions in the light did not lead to inactivation of photosynthesis (Fig. 8).

Cyanobacteria in stromatolites thus deactivate photosynthetic activity after burial due to dark and anaerobic conditions. However, they seem to cope with these conditions quite well, as they reactivate photo-

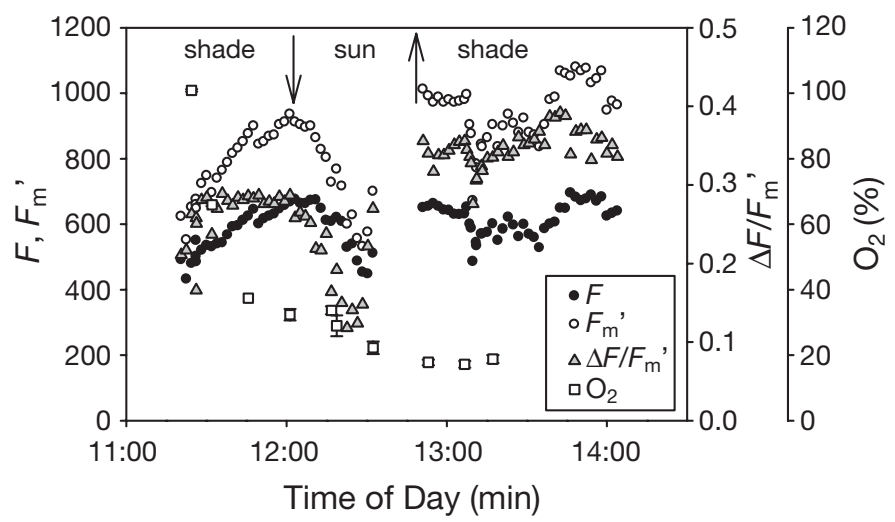

Fig. 8. Changes in $F, F_{\mathrm{m}}{ }^{\prime}$ and $\Delta F / F_{\mathrm{m}}{ }^{\prime}$ in full sunlight during a decrease in oxygen conditions induced by bubbling with $\mathrm{N}_{2}$ gas. At the downward arrow the bottle was placed in direct sunlight and at the upward arrow the bottle was returned to the shade. Note that $\Delta F / F_{\mathrm{m}}{ }^{\prime}$ only reacted to irradiance, but not to $\left[\mathrm{O}_{2}\right]$. The $\mathrm{O}_{2}$ concentration is the average of a triplicate, and the standard deviation, although plotted, is generally smaller than the size of the symbols. The fiberoptic tip of the DIVINGPAM fluorometer was placed $4 \mathrm{~mm}$ above the stromatolite surface at a small angle, in order to avoid shading of the surface by the fiberoptics. Unfortunately, the light data of the LiCor data logger were lost due to damage to the data logger 
synthesis quickly, although the reactivation seems to occur in a 2-step process: an initial phase, which is completed within 1 to $2 \mathrm{~h}$ under the conditions we tested and which is characterised by a quick recovery to a stable but lowered $F_{\mathrm{v}} / F_{\mathrm{m}}$, and a second phase, which must follow, as $F_{\mathrm{v}} / F_{\mathrm{m}}, \mathrm{ETR}_{\max }$ and $\alpha$ of the reactivated samples were all still below the control values (Table 1). This second recovery phase was either very slow or was characterised by a delay and not observed by us. On the other hand, it cannot be excluded that part of the cyanobacteria did die during the burial event, but that these dead cyanobacteria or their chlorophyll breakdown products contributed to the background fluorescence, thus lowering the measured PSII quantum efficiencies. This requires further study.

To our knowledge this is the first study investigating the inactivation/reactivation kinetics of photosynthesis of the stromatolite cyanobacterial community using variable fluorescence techniques, although one similar study investigated the reactivation of PSII activity upon rehydration of cyanobacteria in beach rock microbialites (Schreiber et al. 2002). Although epiphytic diatoms could be found on the stromatolites, the surface community of eukaryotic algae was absent from samples that had been buried, suggesting that the epiphytes cannot withstand the abrasive forces imposed by the burial events. The signals we measured were thus obtained from the cyanobacterial component of the stromatolites. The generally low apparent maximum $F_{\mathrm{v}} / F_{\mathrm{m}}$ values characteristic for cyanobacteria corroborate this.

Interpretation of fluorescence kinetics in cyanobacteria is complicated by state transition (Campbell et al. 1998) and by the fact that they can use the thylakoid membranes both for photosynthesis and respiration (Scherer 1990). The PSII antenna consists of phycobilisomes, whereas the majority of the PSI antennae consists of chlorophyll $a$. Both photosystems display a different excitation spectrum, and, in order to achieve a balanced excitation pressure, state transitions occur (Allen 1992, Campbell et al. 1998, Allan \& Pfann- schmidt 2000). The high fluorescent state (State 1) is induced when the plastoquinone (PQ) pool is oxidised by preferential excitation of PSI. Most cyanobacteria are in the low fluorescent state (State 2) in the dark (Schreiber et al. 1995, Campbell et al. 1998), because respiration causes a reduction of the PQ and the primary electron acceptor of PSII, $\left(Q_{\mathrm{A}}\right)$ pool. During the inactivation process, oxygen plays an important role: as long as oxygen is present, no inactivation takes place. If microbial activity decreases the oxygen concentration slowly after burial, this will prevent re-oxidation of the PQ-pool, thus fixing the $P Q$ and also $Q_{A}$ in a reduced state. This will also initiate 2 simultaneously occurring processes: the reduction of the PQ pool initiates a transition from State 1 to State 2, thus a decrease in both $F$ and $F_{\mathrm{m}}$, whereas the reduction of the $\mathrm{Q}_{\mathrm{A}}$ pool will lead to closure of the PSII reaction centre, causing a rise in $F$. Both these processes can be observed in Fig. 7 , where the decrease in both $F$ and $F_{\mathrm{m}}$ between 20 and $45 \mathrm{~min}$ are dominated by the State 1 to State 2 transition, whereas the slow rise in $F$ between 0.6 and $2.5 \mathrm{~h}$ is caused by a simultaneous reduction of the $Q_{\mathrm{A}}$ pool, causing $F$ to rise, and the State 1 to 2 transition, causing $F$ and $F_{\mathrm{m}}$ to drop.

For the reactivation process, both light and oxygen are necessary. This can be explained by assuming that Rubisco needs to be activated by the enzyme Rubisco activase (Salvucci et al. 1985). This light-activated enzyme requires ATP, and its activity is thus related to the energy charge (Salvucci \& Ogren 1996, Jensen 2000). ATP generation can be achieved by electron flow from PSI to $\mathrm{O}_{2}$ via ferredoxin (the Mehler reaction), leading to zero net $\mathrm{O}_{2}$ exchange (Asada 2000). This activation of Rubisco will generate PSI activity, thus inducing re-oxidation of $\mathrm{PQ}$ and $\mathrm{Q}_{\mathrm{A}}$, and this will restore variable fluorescence. However, as not all cyanobacteria contain the rca gene for this enzyme (Li et al. 1999), and no published genetic information is available for the strains found in stromatolite: this explanation is our working hypothesis. On the other hand, Lyngbya spp. do occur in stromatolites, and $L$. estuarii CCY96106 contains a rca-like gene, which has a very high similarity $(80 \%)$ with the Anabaena rca-gene (J. C. Kromkamp unpubl. data). Theoretically, the renewed presence of oxygen could also have stimulated respiratory activity (in a form similar to chlororespiration), leading to a partial re-oxidation of the PQ pool, which will also lead to restoration of some variable fluorescence. Both mechanisms were invoked by Schreiber et al. (2002) to be responsible for the restoration of PSII activity in their 
beach rock community. However, in our case, oxygen alone was not sufficient to restore PSII activity: light was necessary as well, and very low intensities caused hardly any reactivation, especially in samples that had been buried for several days. This reactivation caused a State 2 to State 1 transition, which is clearly visible in Fig. 6 as a rapid initial rise in both $F$ and $F_{\mathrm{m}}{ }^{\prime}$ of about $10 \%$ at the onset of $77 \mu \mathrm{mol}$ photons $\mathrm{m}^{-2} \mathrm{~s}^{-1}$. This rise in $F$ was followed by a substantial decrease, caused by a partial re-oxidation of the PQ pool. Theoretically, it cannot be excluded that toxicity by sulphide might have played a role in the inactivation and reactivation, as it is known to inhibit photosynthesis. However, matforming cyanobacteria, which can use sulphide as an electron donor for PSI in the light, seem to cope with high sulphide concentrations in general rather well (Stal 1995), and one might speculate that cyanobacteria that cannot tolerate sulphide will most likely not occur in these microbial communities.

\section{CONCLUSIONS}

Stromatolites thus seem well equipped to survive periods of burial, at least of a few days, as we did not investigate burial periods lasting several weeks or longer. Due to microbial oxygen consumption under the sand, PSII will become inactivated, but when the sand is removed by the currents and stromatolites are exposed to normal seawater conditions recovery can be very quick. The anoxic conditions will reduce $P Q$ and $Q_{A}$ pools, leading to a disappearance of variable fluorescence and thus of photosynthetic activity. Upon exposure to normal oxic conditions, we think it likely that electron donation from PSI to $\mathrm{O}_{2}$ will generate ATP and this will activate Rubisco, stimulating PSI activity, re-oxidising the PQ pool and thus leading to the recovery of variable fluorescence. The ability of cyanobacteria to survive and recover from burial by sediment might be fundamental to the success of cyanobacteria as stromatolite builders.

Acknowledgements. We thank the crew from the RV 'Walton Smith' for their assistance and the fabulous food. This work was financed by the National Science Foundation project Research Initiative on Bahamian stromatolites (RIBS) and by a travel grant from the Dutch Schure Beijerinck Poppingfund (to J.C.K.). This is NIOO Publication 4040 and RIBS Contribution Number 37.

\section{LITERATURE CITED}

Allen JF (1992) Protein phosphorylation in regulation of photosynthesis. Biochim Biophys Acta 1098:275-335

Allan JF, Pfannschmidt T (2000) Balancing the two photosystems: photosynthetic electron transfer governs transcrip- tion of reaction centre genes in chloroplasts. Philos Trans R Soc Lond B 355:1351-1360

Asada A (2000) The water-water cycle as alternative photon and electron sinks. Philos Trans R Soc Lond B 355: 1419-1431

Awramik SM (1992) The oldest records of photosynthesis. Photosynth Res 33:75-89

Campbell D, Hurry V, Clarke AD, Gustafsson P, Öquist G (1998) Chlorophyll fluorescence analysis of cyanobacterial photosynthesis and acclimation. Microbiol Mol Biol Rev 62:667-683

Consalvey M, Perkins RG, Paterson DM, Underwood GJC (2005) Pam fluorescence: a beginners guide for benthic diatomists. Diatom Res 20:1-22

Eilers PHC, Peeters JCH (1988) A model for the relationship between light intensity and the rate of photosynthesis in phytoplankton. Ecol Model 42:199-215

Forster RM, Kromkamp JC (2004) Modelling the effects of chlorophyll fluorescence from subsurface layers on photosynthetic efficiency measurements in microphytobenthic algae. Mar Ecol Prog Ser 284:9-22

Genty B, Briantais JM, Baker NR (1989) The relationship between quantum yield of photosynthetic electron transport and quenching of chlorophyll fluorescence. Biochim Biophys Acta 990:87-92

Jensen RG (2000) Activation of Rubisco regulates photosynthesis at high temperature and $\mathrm{CO}_{2}$. Proc Natl Acad Sci USA 97:12937-12938

Kromkamp JC, Forster RM (2003) The use of variable fluorescence measurements in aquatic ecosystems: differences between multiple and single turnover measuring protocols and suggested terminology. Eur J Phycol 38:103-112

Li LA, Zianni MR, Tabita FR (1999) Inactivation of the monocistronic rca gene in Anabaena variabilis suggests a physiological ribulose bisphosphate carboxylase oxygenase activase-like function in heterocystous cyanobacteria. Plant Mol Biol 40:467-478

Macintyre IG, Prufert-Bebout L, Reid RP (2000) The role of endolithic cyanobacteria in the formation of lithified laminae in Bahamian stromatolites. Sedimentology 47: 915-921

Paerl HW, Steppe TF, Reid RP (2001) Bacterially mediated precipitation in marine stromatolites. Environ Microbiol 3: 123-130

Perkins RG, Oxborough K, Hanlon ARM, Underwood GJC, Baker NR (2002) Can chlorophyll fluorescence be used to estimate the rate of photosynthetic electron transport within microphytobenthic biofilms? Mar Ecol Prog Ser 228:47-56

Perkins RG, Mouget JL, Lefebvre S, Lavaud J (2006) Light response curve methodology and possible implications in the application of chlorophyll fluorescence to benthic diatoms. Mar Biol 149:703-712

Reid RP, Visscher PT, Decho AW, Stolz JF and 8 others (2000) The role of microbes in accretion, lamination and early lithification of modern marine stromatolites. Nature 406: 989-992

Sakshaug E, Bricaud A, Dandonneau Y, Falkowski PG and 5 others (1997) Parameters of photosynthesis: definitions, theory and interpretatation of results. J Plankton Res 19: $1637-1670$

Salvucci M, Ogren W (1996) The mechanism of Rubisco activase: insights from studies of the properties and structure of the enzyme. Photosynth Res 47:1-11

Salvucci M, Portis A, Ogren W (1985) A soluble chloroplast protein catalyzes ribulosebisphosphate carboxylase/oxygenase activation in vivo. Photosynth Res 7:193-201 
Scherer S (1990) Do photosynthetic and respiratory electron transport chains share redox proteins? TiBS 15:458-462

Schreiber U, Endo T, Mi H, Asada A (1995) Quenching analysis of chlorophyll fluorescence by the saturation pulse method: particular aspects relating to the study of eukaryotic algae and cyanobacteria. Plant Cell Physiol 36: 873-882

Schreiber U, Gademann R, Bird P, Ralph PJ, Larkum AWD, Kuhl M (2002) Apparent light requirement for activation of photosynthesis upon rehydration of dessicated beachrock microbial mats. J Phycol 38:125-134

Editorial responsibility: William Li,

Dartmouth, Nova Scotia, Canada
Serôdio J, Cruz S, Vieira S, Brotas V (2005) Non-photochemical quenching of chlorophyll fluorescence and operation of the xanthophyll cycle in estuarine microphytobenthos. J Exp Mar Biol Ecol 326:157-169

Stal LJ (1995) Physiological ecology of cyanobacteria in microbial mats and other communities. New Phytol 131: $1-32$

Visscher PT, Reid RP, Bebout BM (2000) Microscale observations of sulfate reduction: correlation of microbial activity with lithified micritic laminae in modern marine stromatolites. Geology 28:919-922

Submitted: October 18, 2006; Accepted: March 29, 2007 Proofs received from author(s): June 25, 2007 